\title{
TECNOLOGIA ASSISTIVA E INCLUSÃO DE ESTUDANTES COM PARALISIA CEREBRAL: UM ESTUDO PRELIMINAR $^{1}$
}

Samuel Vinente ${ }^{1}$, Ketlen Júlia Lima da Silva ${ }^{2}$

Universidade Federal de São Carlos - UFSCar, Programa de Pós-Graduação em Educação Especial (PPGEEs), São Carlos, SP. Universidade Federal do Amazonas - UFAM, Curso de Letras, Língua e Literatura Portuguesa, Manaus, AM. E-mail: samueljunior.ns@gmail.com

\section{RESUMO}

Este trabalho apresenta um estudo teórico que objetivou analisar o uso da Tecnologia Assistiva (TA) enquanto facilitador no processo de inclusão escolar de crianças com paralisia cerebral (PC). Foi realizado um levantamento bibliográfico no Banco de Teses e Dissertações do Portal Domínio Público da Fundação de Aperfeiçoamento de Pessoal de Nível Superior (CAPES), compreendendo o período de 2005 a 2010. Foram utilizados os seguintes descritores: paralisia cerebral; ajudas técnicas; recursos pedagógicos; acessibilidade; Tecnologia Assistiva; comunicação alternativa; comunicação suplementar; comunicação aumentativa; comunicação aumentativa e alternativa; comunicação alternativa e ampliada; estratégias e, estratégias de ensino. Com base nos descritores foram selecionados 195 trabalhos, dos quais 167 foram excluídos por serem repetidos ou não responderem aos objetivos do estudo, restando 28. Os resultados apontaram os anos com maior expressividade na publicação: 2007 (oito trabalhos); seguida respectivamente pelo ano de 2009 (seis trabalhos); 2008 (cinco trabalhos); 2010 (cinco trabalhos); e 2006 (apenas quatro). Pode-se verificar que $86 \%$ dos trabalhos foram publicados em instituições da região sudeste, $11 \%$ na região nordeste e $3 \%$ na região sul. Destes, $71 \%$ resultaram de pesquisas de mestrado e $29 \%$ de pesquisas de doutorado. Os autores apontam a necessidade de formação especializada para os educadores que atuam com escolares que apresentam PC e adequação da estrutura física das escolas para a promoção da acessibilidade. Esperase que este estudo contribua na produção e socialização do conhecimento na área da pesquisa em educação especial, proporcionando novos olhares sobre a inclusão escolar.

Palavras-Chave: Educação Especial. Tecnologia Assistiva; Paralisia Cerebral; Políticas Públicas.

\section{ASSISTIVE TECHNOLOGY AND INCLUSION OF STUDENTS WITH CEREBRAL PALSY: APRELIMINARY STUDY}

\begin{abstract}
This paper presents a theoretical study that aimed to analyze the use of Assistive Technology (AT) as a facilitator in the process of school inclusion of children with cerebral palsy (CP). It conducted a literature review in the Bank of Theses and Dissertations Portal of the Public Domain of Higher Education Personnel Training Foundation (CAPES), covering the period 2005 to 2010. The following descriptors were used: cerebral palsy; technical aids; educational resources; accessibility; Assistive technology; alternative communication; additional communication; augmentative communication; augmentative and alternative communication; alternative and expanded communication; strategies and teaching strategies. Based on the descriptors were selected 195 works, of which 167 were excluded because they repeated or do not meet the objectives of the study, remaining 28 . The results indicated the years with greater expressiveness in the publication: 2007 (eight studies); followed respectively by 2009 (six papers); 2008 (five papers); 2010 (five papers); and 2006 (only four). It can be seen that $86 \%$ of works have been published in southeastern institutions, $11 \%$ in the Northeast and $3 \%$ in the south. Of these, $71 \%$ resulted from research master's and $29 \%$ of doctoral research. The authors point out the need for specialized training for educators who work with students who have PC and appropriateness of the physical structure of schools to promote accessibility. It is hoped that this study will contribute in the production and socialization of knowledge in the field of research in special education, providing new perspectives on school inclusion.
\end{abstract}

Keywords: Special Education. Assistive technology; Cerebral palsy; Public policy

\footnotetext{
${ }^{1}$ Pesquisa de Iniciação Científica apoiada pelo Conselho Nacional de Desenvolvimento Científico e Tecnológico (CNPq), sob o Processo no $136843 / 2013-1$.
} 


\section{INTRODUÇÃO}

Esta pesquisa integrou as ações do projeto Tecnologia Assistiva (TA) e Comunicação Alternativa: contribuições para a inclusão escolar de crianças com paralisia cerebral (PC), desenvolvido no âmbito do Programa Institucional de Bolsas para a Iniciação Científica (PIBIC) da Universidade Federal do Amazonas (UFAM), com apoio do Conselho Nacional de Desenvolvimento Científico e Tecnológico (CNPq) sob o processo no 136843/2013-1.

O referido estudo objetivou com base na literatura científica analisar o uso da TA enquanto facilitador no processo de inclusão escolar de crianças com PC. De acordo com a atual legislação brasileira, a PC integra o grupo da deficiência física. Em um contexto mais amplo, a deficiência física é definida pelo Decreto no 3.298/1999 como uma:

[...] alteração completa ou parcial de um ou mais segmentos do corpo humano, acarretando comprometimento da função física, apresentando-se sob a forma de paraplegia, paraparesia, monoplegia, monoparesia, tetraplegia, tetraparesia, triplegia, triparesia, hemiplegia, hemiparesia, ostomia, amputação ou ausência de membro, paralisia cerebral, nanismo, membros com deformidade congênita ou adquirida, exceto as deformidades estéticas e as que não produzam dificuldades para 0 desempenho de funções (BRASIL, 1999, art. 4으, inciso I).

Sendo a PC um subgrupo dentro da deficiência física, o termo PC passa a ser definido pela Associação Brasileira de Paralisia Cerebral (ABPC) como "um termo geral que engloba manifestações clínicas muito variadas, que têm em comum a dificuldade motora em consequência a uma lesão cerebral" (ABPC, 2015, $s / p)$.

No quadro clínico da deficiência física, dependendo da distribuição do comprometimento motor, a PC pode ser classificada em três tipos: (1) tetraparesia comprometimento nos membros superiores e inferiores; (2) diparesia - comprometimento mais acentuado nos membros inferiores; e (3) hemiparesia - comprometimento de um hemisfério do corpo, podendo ser esquerdo ou direito. (ABPC, 2015, s/p).

Partindo da concepção da deficiência a partir da ótica dos direitos humanos, compreende-se a escolarização desses estudantes, atualmente integrantes do públicoalvo da Educação Especial (PAEE) ${ }^{2}$, como um direito universal. Nessa perspectiva, a legislação educacional brasileira avançou no sentido de garantir direitos sociais como a educação e saúde para as pessoas com deficiência.

A Constituição Federal assegura "o atendimento educacional especializado [...] preferencialmente na rede regular de ensino". (BRASIL, 1988, art. 208, inciso III). Tal atendimento é definido pelo Decreto no 7.611, de 17 de novembro de 2011, como o "conjunto de atividades, recursos de acessibilidade e pedagógicos organizados institucional e continuamente [...]" (BRASIL, 2011, art. 1ㅇ).

A oferta do Atendimento Educacional Especializado (AEE) é prevista na legislação a partir de duas formas: (a) complementar - com apoio permanente e limitado de estudantes com deficiência e transtornos globais do desenvolvimento nas salas de recursos multifuncionais, e; (b) suplementar aos estudantes com altas habilidades ou superdotação. (BRASIL, 2011).

Nessa perspectiva, para potencializar o atendimento de estudantes com PC, por exemplo, o uso de recursos da TA favorece a autonomia e a participação desses estudantes no ensino regular. O artigo 3, inciso III do Decreto no 7.611/2011 normatiza que um dos objetivos do AEE seria "[...] fomentar o desenvolvimento de recursos didáticos e pedagógicos que eliminem as barreiras no processo de ensino e aprendizagem" (BRASIL, 2011, art. 3으, inciso III).

Com base na eliminação de barreiras impostas às pessoas com deficiência, surge como um campo interdisciplinar a terminologia ajudas técnicas, que posteriormente passar a ser denominada TA. Segundo o Comitê de Ajudas Técnicas - CAT (BRASIL, 2007), grupo esse constituído pela Secretaria Especial de Direitos

\footnotetext{
2 O Decreto no 7.611, de 17 de novembro de 2011, passa a considerar público-alvo da Educação Especial (PAEE) os estudantes com deficiência, transtornos globais do desenvolvimento e altas habilidades ou superdotação. (BRASIL, 2011).
} 
Humanos da presidência da República, o conceito de TA adotado recentemente representa:

[...] uma área do
conhecimento de
característica interdisciplinar,
que engloba recursos,
produtos, metodologias,
estratégias, práticas e serviços
que objetivam promover a
funcionalidade, relacionada à
atividade e participação, de
pessoas com deficiência,
incapacidades ou mobilidade
reduzida, visando sua
autonomia, independência,
qualidade de vida e inclusão
social. (BRASIL, 2007, p. 3).

A partir dessa ampla área do conhecimento, de característica interdisciplinar, muitos estudos vêm contribuindo com a área da educação especial no sentido de assegurar formação inicial e continuada de professores para utilização dos recursos de TA e implementação de recursos específicos para a potencialização do AEE de estudantes com deficiência (MANZINI; SANTOS, 2002; MANZINI, 2005; GALVÃO FILHO, 2008; PONSONI, 2010; SARTORETTO, BERSCH, 2010; ROCHA; DELIBERATO, 2012).

Mesmo que a atual terminologia seja ainda recente torna-se necessário identificar na produção científica em educação e educação especial subsídios teórico-metodológicos para a inclusão escolar de estudantes com PC. Nessa perspectiva, pretendeu-se no trabalho caracterizar a produção científica em educação no período de 2005 a 2010 na área de TA com vistas à inclusão escolar de estudantes com PC nos sistemas de ensino.

\section{MÉTODO}

O trabalho resulta da etapa de aprofundamento teórico-metodológico de um projeto aprovado pelo Comitê de Ética e Pesquisa da Universidade Federal do Amazonas (UFAM), sob o Certificado de Apresentação para Apreciação Ética (CAAE) no 15598613.9.0000.5020. Apresentamos o método estruturado nos seguintes tópicos: (a) delineamento; (b) fontes de informação; (c) período; (d) procedimentos de coleta dos dados; (e) procedimento de análise dos dados:

\section{Delineamento}

O estudo em questão trata-se de uma pesquisa bibliográfica. De acordo com Gil (2002), a pesquisa bibliográfica é aquela desenvolvida a partir de material já produzido como, por exemplo, livros, dissertações, teses, revistas e artigos científicos. Nesse contexto, o presente artigo enquanto revisão de literatura busca identificar "[...] relações, contradições, lacunas e inconsistências na literatura, além de indicar sugestões para a solução de problemas". (HOHENDORFF, 2014, p. 40).

As vantagens da utilização da pesquisa bibliográfica envolvem a permissão da ampla investigação dos fenômenos, o que não ocorre em pesquisas mais diretas, além do conhecimento de fatos maios diversificados (GIL, 2002).

Nessa perspectiva, uma revisão de literatura buscando analisar a produção científica sobre o uso dos recursos de TA e CA para a inclusão escolar de estudantes com PC contribui para que sejam observadas lacunas e sub-áreas onde os trabalhos encontram-se saturados, buscando-se assim, avançar na produção do conhecimento na área de educação especial.

\section{Fontes de Informação}

A pesquisa foi realizada no Banco de Teses e Dissertações do Portal Domínio Público, vinculado à Fundação de Aperfeiçoamento de Pessoal de Nível Superior (CAPES). Esse portal é uma biblioteca digital com mais de 94.000 títulos cadastrados disponibilizados por meio de um software livre no endereço eletrônico: http://www.dominiopublico.gov.br/pesquisa/.

\section{Período}

Foram incluídos na amostragem os trabalhos publicados no Banco de Teses e Dissertações do Portal Domínio Público (CAPES) entre o período de 2005 a 2010, os quais versavam sobre a construção de recursos pedagógicos adaptados como fatores relevantes para a inclusão escolar de estudantes PAEE.

\section{Procedimentos de Coleta de dados}

A fim de obter um amplo número de trabalhos na pesquisa realizada no Banco de Teses de Teses e Dissertações do Portal Domínio Público da CAPES optou-se pela utilização dos seguintes descritores: (a) paralisia cerebral; (b) ajudas técnicas; (c) recursos pedagógicos; (d) acessibilidade; (e) tecnologia assistiva; (f) 
comunicação alternativa; (g) comunicação suplementar; (h) comunicação aumentativa; (i) comunicação aumentativa e alternativa; (j) comunicação alternativa e ampliada; (I) estratégias; $e,(m)$ estratégias de ensino.

Os descritores foram utilizados no sítio eletrônico do Banco de Teses e Dissertações do Portal Domínio Público (CAPES), de forma isolada. Para que os trabalhos integrassem o escopo de análise deveriam apresentar algum dos descritores selecionados no título ou nas palavras-chave que compunham o resumo.
Sendo assim, inicialmente foram encontrados aproximadamente 195 trabalhos. Destes, aproximadamente 167 eram repetidos ou não versavam sobre a temática. Após serem excluídos, restaram 28 trabalhos que foram analisados. Os resultados da busca realizada no Banco de Teses e Dissertações do Portal Domínio Público estão enumerados na Tabela 1, a partir do uso dos descritores selecionados:

Tabela 1. Panorama da busca realizada no Banco de Teses e Dissertações do Portal Domínio Público

\begin{tabular}{|c|c|c|c|c|c|}
\hline Descritor & & Resumos & Títulos & Total de Excluídos & Total do Refinamento \\
\hline Paralisia Cerebral & & 19 & 19 & 20 & 18 \\
\hline Ajudas Técnicas & & 0 & 0 & 0 & 0 \\
\hline Recursos Pedagógicos & & 2 & 3 & 5 & 0 \\
\hline Acessibilidade & & 7 & 6 & 13 & 1 \\
\hline Tecnologia Assistiva & & 6 & 5 & 7 & 4 \\
\hline Comunicação Alternativa & & 6 & 5 & 8 & 3 \\
\hline Comunicação Suplementar & & 3 & 3 & 5 & 1 \\
\hline Comunicação Aumentativa & & 0 & 1 & 1 & 0 \\
\hline $\begin{array}{l}\text { Comunicação Aumentativa } \\
\text { Alternativa }\end{array}$ & $\mathrm{e}$ & 0 & 1 & 1 & 0 \\
\hline $\begin{array}{l}\text { Comunicação Alternativa } \\
\text { Ampliada }\end{array}$ & e & 1 & 2 & 3 & 0 \\
\hline Estratégias & & 46 & 60 & 105 & 1 \\
\hline Estratégias de Ensino & & 7 & 4 & 11 & 0 \\
\hline TOTAL & & \multicolumn{2}{|c|}{195} & 167 & 28 \\
\hline
\end{tabular}

Fonte: Elaboração própria, com base nos dados da pesquisa.

O total de trabalhos encontrados que possuíam os descritores selecionados tanto nas palavras-chave quanto nos títulos foi de 195. Após leitura criteriosa dos títulos e resumos foram excluídos os trabalhos repetidos e que não respondiam aos objetivos propostos (167), restando apenas 28 trabalhos.

\section{Procedimentos de Análise dos dados}

O refinamento dos dados foi necessário tendo em vista que alguns estudos não condiziam com o objetivo proposto no presente estudo, principalmente quanto aos descritores contidos no título ou nas palavras-chave, sendo então conveniente excluí-los. Assim sendo, encontrouse grande variedade de temas sobre TA, porém muitos não tratavam de trabalhos dessas áreas para suporte à inclusão escolar de estudantes com PC.

O material encontrado foi organizado em um protocolo elaborado pelos pesquisadores, documento esse que continha os seguintes campos a serem preenchidos: (a) título do trabalho; (b) autoria; (c) ano da publicação; (d) instituição depositária; (e) programa de pósgraduação; (f) curso; (g) tipo de trabalho dissertação ou tese.

Os dados foram analisados à luz do referencial teórico da área. Os materiais obtidos foram lidos e organizados sistematicamente para compor o quadro de análise dos dados. Tal análise foi fundamentada com base no aporte teórico de Bordgan e Biklen (1994). Os materiais foram descritos, quantificados, distribuídos em categorias e, posteriormente, as informações foram agrupadas. Os resultados e as discussões serão detalhados a seguir.

\section{RESULTADOS E DISCUSSÕES}

Os resultados são apresentados nas seguintes categorias: (a) caracterização dos trabalhos publicados no Portal; e, (b) implicações teórico-práticas dos estudos desenvolvidos. No primeiro tópico serão tratados aspectos sobre o ano de maior predominância nas publicações, gênero dos participantes e instituições 
participantes. No segundo item serão discutidos aspectos dos trabalhos sobre a inclusão escolar de estudantes com PC tendo em vista o uso dos recursos de TA.
Caracterização dos trabalhos publicados no Portal

De acordo com os dados da pesquisa, as publicações encontradas eram relativas aos anos de 2006, 2007, 2008, 2009 e 2010. Com base no gráfico 1, pode-se observar a distribuição dos trabalhos por ano:

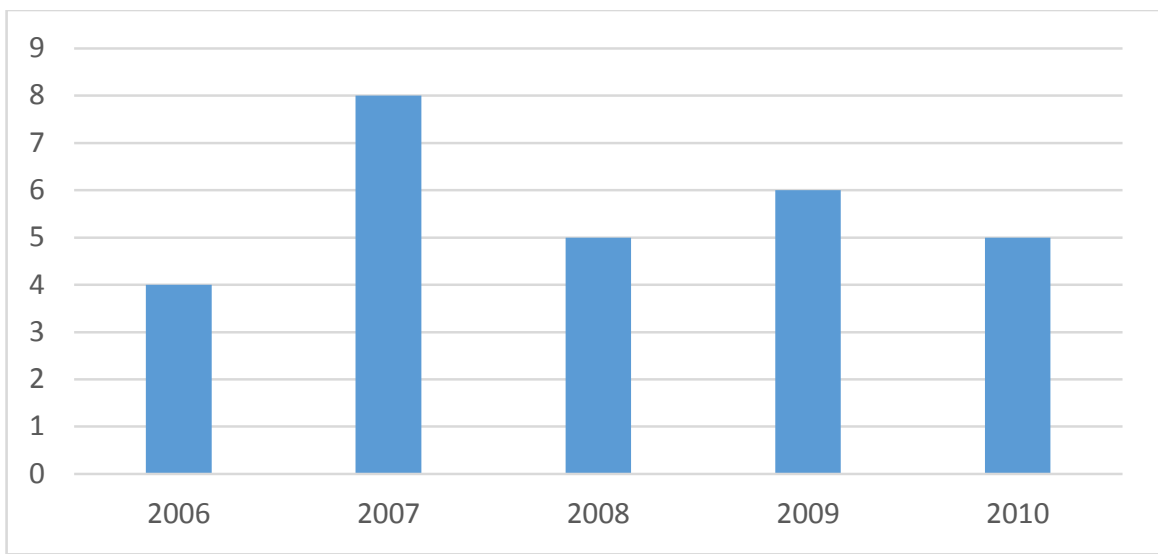

Gráfico1. Distribuição das publicações por ano (2006 a 2010)

Fonte: Elaboração própria, com base nos dados da pesquisa

Com base nos dados do Gráfico 1 pode-se verificar que a predominância de trabalhos publicados integrou a produção bibliográfica do ano de 2007 (oito trabalhos), seguida respectivamente pelo ano de 2009 (seis trabalhos), 2008 (cinco trabalhos), 2010 (cinco trabalhos) e 2006 (apenas quatro).
Foi possível verificar também a predominância de artigos publicados por pesquisadores do gênero feminino, 0 que totalizou $82 \%$ se comparado ao número de trabalhos publicados por pesquisadores do gênero masculino (18\%), como pode ser observado no Gráfico 2:

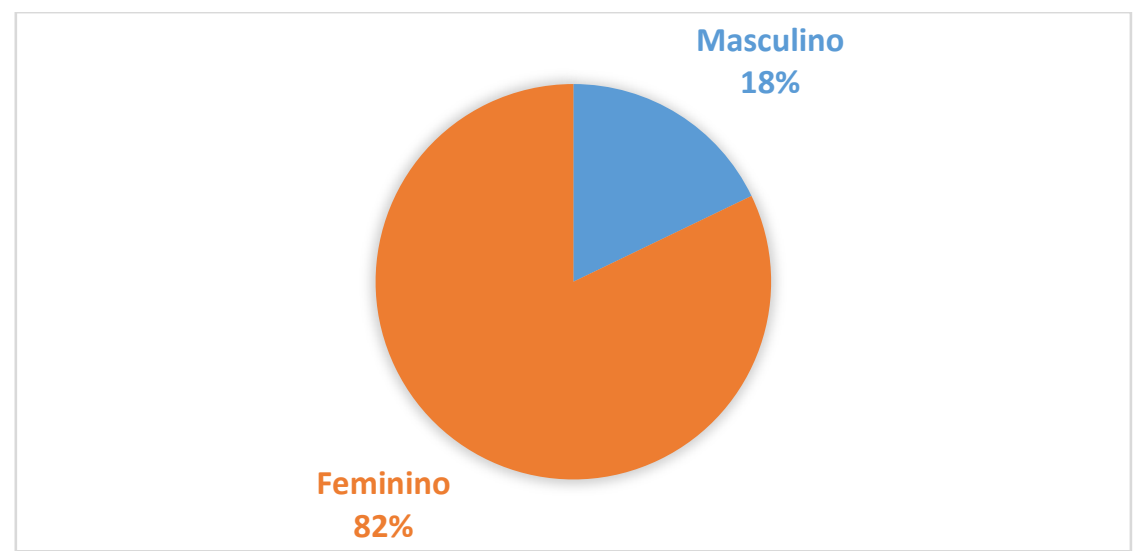

Gráfico 2. Gênero dos pesquisadores que publicaram sobre a temática Fonte: Elaboração própria com base nos dados da pesquisa.

Dentre as Universidades que possuíam depositários das publicações relacionadas ao tema em questão estão: Universidade Federal de São Carlos (UFSCar); Universidade Federal do Rio Grande do Norte (UFRN); Universidade de Uberaba (UNIUBE); Universidade Metodista de Piracicaba (UNIMEP); Universidade do Vale do
Itajaí (UNIVALI); Universidade Federal do Ceará (UFC); Universidade Estadual Paulista Júlia de Mesquita Filho (UNESP); Pontifícia Universidade Católica (PUC/SP); Universidade do Estado do Rio de Janeiro (UERJ) e Universidade Federal da Bahia (UFBA). A distribuição pode ser observada no Gráfico 3: 


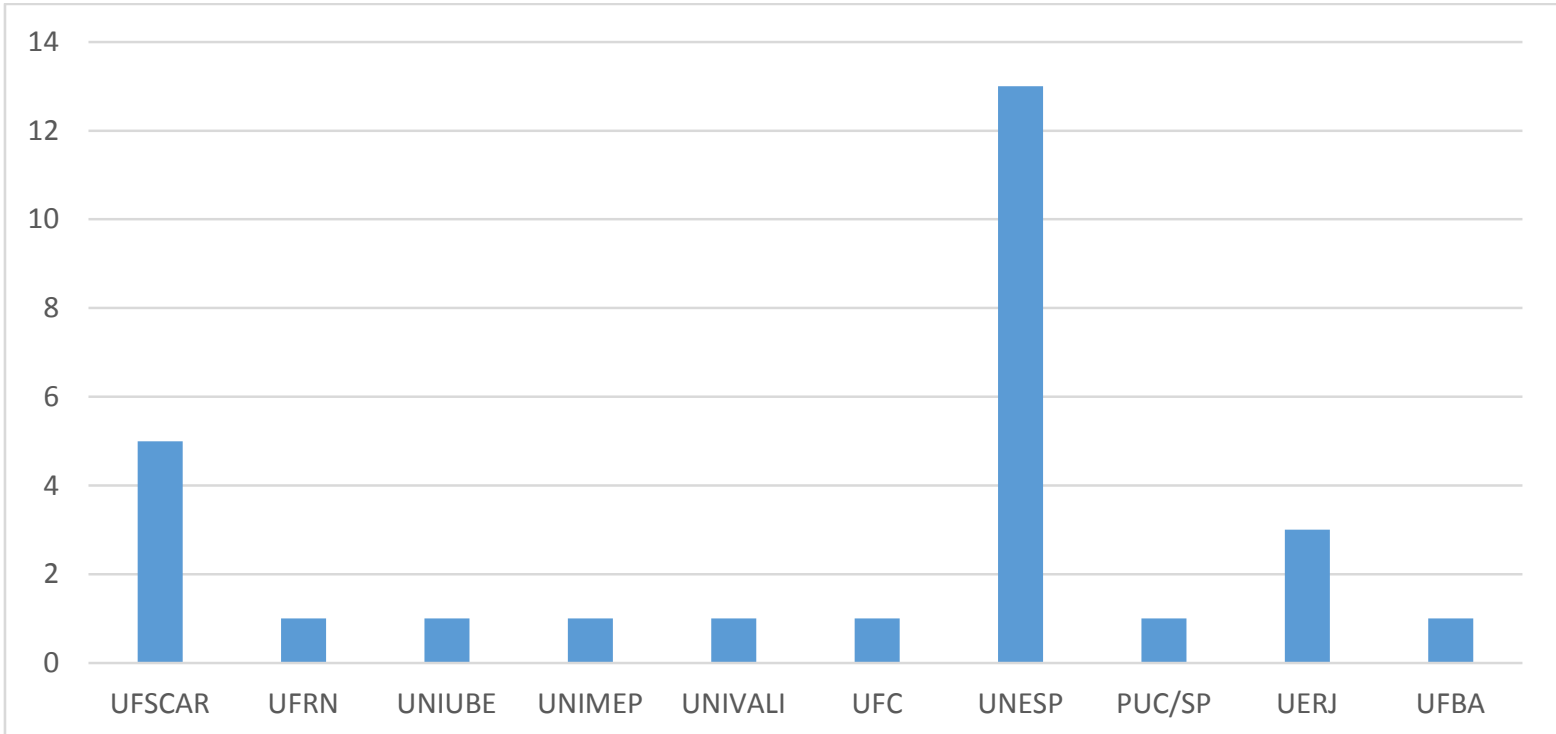

Gráfico 3. Distribuição das publicações por instituição de pesquisa Fonte: Elaboração própria com base nos dados da pesquisa.

Como foi na ilustrado no Gráfico 3, há uma predominância de trabalhos sobre Tecnologia Assistiva na UNESP (13), vale sinalizar que a maioria dos estudos foram publicados no Campus Marília. A UFSCar concentra cinco (5) trabalhos e a UERJ três (3). As outras instituições (UFRN, UNIUBE, UNIMEP, UNIVALI, UFC, PUC/SP e UFBA) concentram um trabalho cada.

A partir da análise dos dados tabulados no Gráfico 3, se pode verificar que $86 \%$ dos trabalhos encontram-se publicados em instituições da região sudeste, $11 \%$ na região nordeste e $3 \%$ na região sul. As regiões norte e centro-oeste não apresentaram publicações no Portal Domínio Público durante o período da pesquisa, o que sinaliza a importância de estudos regionais e locais que se debrucem a analisar a realidade do processo de inclusão desses estudantes a partir do uso dos recursos de TA.

No gráfico 4 é possível observar a distribuição dos trabalhos desenvolvidos nos programas de pós-graduação em educação e educação especial, a partir de cursos de mestrado e doutorado:

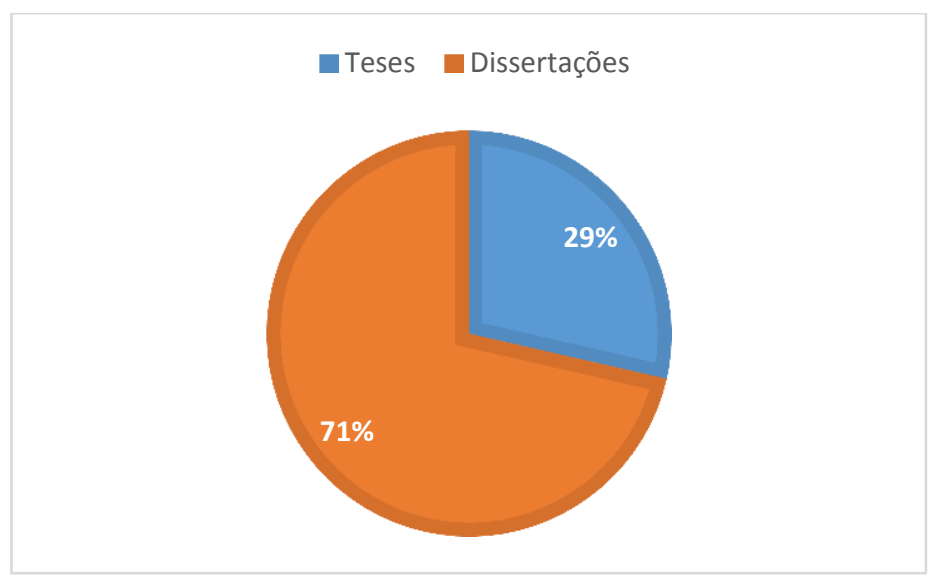

Gráfico 4.Distribuição das publicações por curso (mestrado e doutorado)

Fonte: Elaboração própria, com base nos dados da pesquisa.

Por meio dos dados apontados no Gráfico 4 , é possível observar que $71 \%$ dos trabalhos encontrados no período resultam de pesquisas de mestrado e $29 \%$ resultam de pesquisas de doutorado.
Implicações teórico-práticas dos estudos desenvolvidos

Aprendemos aquilo que vivenciamos e a oportunidade de relações e correlações, 
exercício, observações, autoavaliação e aperfeiçoamento na execução de tarefas fará a diferença na qualidade e quantidade de coisas que as estudantes com PC podem aprender (BERSCH; MACHADO, 2007).

Os dados do estudo sinalizaram que contribuir no desenvolvimento destes educandos é o marco inicial para potencializar uma aprendizagem significativa. $O$ trabalho de Alves (2009), ao decorrer sobre a necessidade de desenvolver as potencialidades dos educandos com PC, refere-se à importância da inclusão social e pedagógica, mas refere-se também à inclusão do indivíduo consigo mesmo, a aceitação de suas dificuldades, a conscientização de suas capacidades atuais e a construção do desenvolvimento de suas habilidades (ALVES, 2009).

As contribuições de Bersch e Machado (2007) apontam que a estimulação precoce favorece à criança com PC inúmeras possibilidades de aprendizagem e desenvolvimento ainda na primeira infância. Nessa perspectiva, estudantes com PC, que tenham comprometimento global leve, movimentam-se com independência, realizando atividades motoras finas, tais como desenhar, encaixar, recortar, colar, sendo capazes de construir frases com mais de duas palavras e demonstrando, além disso, boa adaptação social.

Ao se levar em consideração os aspectos referentes aos direitos humanos que consubstanciam a inclusão escolar desses estudantes, Bersch e Machado (2007) evidenciam que o professor deve procurar ter informações sobre as especificidades de cada aluno. Segundo as pesquisadoras, devemos "[...] distinguir lesões neurológicas não evolutivas, como a paralisia cerebral ou traumas medulares, de outros quadros progressivos como distrofias musculares ou tumores que agridem o Sistema Nervoso" (BERSCH; MACHADO, 2007, p. 23).

No espaço das salas de recursos multifuncionais destinadas ao $\mathrm{AEE}$, o aluno com PC deve experimentar várias opções de equipamentos até que encontre o que melhor se ajusta à sua necessidade e condição. Sendo assim, a TA contribui de forma significativa para uma inclusão efetiva deste educando. $\mathrm{Na}$ perspectiva de Bersch e Machado (2007), os professores são recursos humanos que podem possibilitar aos alunos a autonomia, segurança e a comunicação por meio do uso desses recursos.
A inclusão de alunos com necessidades educacionais especiais perpassa os conceitos de acessibilidade estrutural e atitudinal, objetivando - AEE nas salas de recursos multifuncionais (BRASIL, 2008). As pesquisas realizadas nesse contexto (SARTORETTO; BERSCH, 2010; VINENTE, 2012; MATOS, 2012; GUERREIRO, 2012) apontam a necessidade de investimentos de órgãos governamentais e não governamentais na formação de educadores para a inclusão (MAZOTTA, 2005).

A produção científica sobre a inclusão de alunos PAEE cresceu nos últimos anos de forma significativa. Muitos dos trabalhos encontrados problematizam questões como a formação docente (MOTA; 2007; ALPINO, 2008; ALVES, 2009), a acessibilidade, os recursos pedagógicos adaptados, a implementação das políticas públicas e o acesso e permanência de pessoas com deficiência na escola de ensino regular.

O termo TA vem sendo empregado, atualmente, caracterizando-se como substitutivo ao termo "ajudas técnicas", visualizado principalmente em diversas publicações nas áreas de educação, saúde e arquitetura. Verifica-se que a temática sobre a inclusão de pessoas com PC em ambientes escolares e não escolares vem se configurando relevante na atualidade, principalmente no debate contemporâneo sobre o respeito e valorização da diversidade (VINENTE, 2012).

Nesse cenário, os estudos sobre TA enfatizam a necessidade de inserir recursos, serviços e estratégias na educação especial e inclusiva para colaborar com o processo de aprendizagem de alunos com PC (MOTA, 2007; ALPINO, 2008; JESUS, 2009; ROCHA; DELIBERATO, 2012). A primeira etapa para a implementação da TA deve permitir entender a situação que envolve o aluno, a fim de ampliar a sua participação no processo de ensino-aprendizagem.

As pesquisas desenvolvidas nesse contexto enfatizam a necessidade do envolvimento de profissionais especializados em diferentes áreas do conhecimento para o trabalho com pessoas com deficiência (ROCHA; DELIBERATO, 2012). As autoras apontam as diferentes etapas dos serviços de TA, tais como: a avaliação e identificação das habilidades e necessidades; prescrição e confecção dos recursos; acompanhamento contínuo para modificação desses recursos sempre que necessário para melhor utilização. 
A comunicação alternativa é parte desse processo, sendo destinada "[...] à ampliação de habilidades de comunicação [...]" (SARTORETTO; BERSCH, 2010). É destinada a pessoas sem fala ou sem escrita funcional, com defasagem entre sua necessidade comunicativa e sua habilidade em falar e escrever (BERSCH; SCHIRMER, 2005). No contexto educacional, para descrever a utilização de recursos pedagógicos de acessibilidade na escola, é preciso estar atento às características do aluno, à atividade que o professor propõe na sala de aula e aos objetivos educacionais que pretendem ser alcançados (SARTORETTO; BERSCH, 2010).

Para Gomes e Barbosa (2006), “a existência de barreiras a serem transpostas para efetivação da proposta escolar inclusiva é compreensível, uma vez que se trata de um processo [...] recente no Brasil e ainda em andamento". Sendo assim, ainda é necessário que pesquisas sejam desenvolvidas principalmente nas regiões em que não foi possível verificar estudos sobre a temática desenvolvidos (norte e centro-oeste) para que se obtenha um panorama de como se implementam as políticas inclusivas. Sem recursos pedagógicos, de TA não há inclusão efetiva, pois, esses itens são necessários para a relação entre o deficiente e a sociedade.

O estudo de Ponsoni (2010), ao pesquisar a comunicação suplementar e alternativa no discurso narrativo do aluno com PC, por meio da aplicação de um programa de intervenção do recurso de comunicação, verificou que o ensino dos elementos do discurso narrativo proporcionou o aumento das habilidades de narrar relato de experiência pessoal e histórias infantis. A autora também visualizou que o programa de intervenção contribuiu para o aumento das habilidades expressivas dos participantes da pesquisa.

Alves (2009) identificou os efeitos do uso da TA no contexto da escolarização do aluno com PC a partir de sua própria percepção, do seu cuidador e de seu professor. 0 estudo revelou que professores, cuidadores e as crianças participantes reconheceram que esses recursos favorecem 0 processo de escolarização dos escolares com PC, sendo um recurso auxiliar à produção, a participação e a escolarização.

A utilização das representações sociais nas ações de formação de professores pode ser uma estratégia para promover mudanças nas representações destes profissionais e, consequentemente aprimorar 0 trabalho pedagógico realizado com os alunos com PC nas escolas regulares (SILVA, 2008). Isto se ocasiona de forma mais efetiva dependendo do caso clínico do escolar, ou seja, discentes com quadros clínicos mais severos apresentam maiores dificuldades para inclusão nas escolas regulares, sendo assim formação inicial e continuada é um dos pontos fundamentais para a garantia da inclusão e escolarização (VINENTE, 2012).

\section{CONSIDERAÇÕES FINAIS}

Garantir a inclusão plena de alunos com deficiência é um dos desafios postos no cotidiano das escolas atualmente. Estudos comprovam que gestores, docentes, familiares de pessoas com deficiência e demais profissionais da educação carecem de maior acesso às informações sobre a inclusão escolar e de especialização para atuação no Atendimento Educacional Especializado - AEE, proposto na Constituição Federal (BRASIL, 1988), na Política Nacional de Educação Especial na perspectiva da Educação Inclusiva (BRASIL, 2008) e no Decreto 7.611/2011 (BRASIL, 2011).

A educação especial deve garantir os serviços de apoio especializado voltado a eliminar as barreiras que possam obstruir o processo de escolarização de estudantes PAEE (BRASIL, 2011). A partir disto, destacam-se os recursos da TA como subsídios necessários para a inclusão escolar de alunos com PC, no sentido de favorecer o ensino (professor) e a aprendizagem significativa (educando), oferecendo novas estratégias e serviços de apoio para a escolarização desse público-alvo.

No artigo 3으, inciso III do Decreto 7.611/2011, o legislador afirma que, um dos princípios da educação especial é fomentar o desenvolvimento de recursos didáticos e pedagógicos que eliminem as barreiras no processo de ensino-aprendizagem. As investigações com vistas à criação de softwares educativos para pessoas com deficiências ainda estão em fase de implementação, por isso é necessário que mais estudos contribuam no sentido de aumentar a produção bibliográfica e técnica nesta área do conhecimento.

O uso dos recursos da TA para inclusão destes escolares pode contribuir no sentido de implementação das políticas de inclusão e na disposição de recursos apropriados para a sala de aula que auxiliem docentes e discentes neste processo. Dependendo do tipo clínico, a PC pode afetar, além do aspecto motor e psicomotor, o 
desenvolvimento da linguagem, e outros comprometimentos no que tange à locomoção, equilíbrio, coordenação/precisão dos movimentos (BRANDÃO, 1992).

Os escolares com PC podem participar das aulas e ter acesso ao processo de escolarização, inclusive, há estudos que comprovam que dependendo da área afetada e do caso clínico, estes alunos aprendem e se desenvolvem no cotidiano da escola comum. Os recursos pedagógicos acessíveis consolidam a inclusão destes alunos no ensino regular. $O$ estudo reveste-se de importância por permitir aos pesquisadores a visualização acerca do uso da TA e Comunicação Alternativa nas salas de recursos multifuncionais para a inclusão de alunos com PC.

Espera-se que esta pesquisa contribua com a produção de conhecimentos na área de educação especial na perspectiva da educação inclusiva, oferecendo subsídios para a produção científica no contexto de novos estudos que respondam as lacunas presente na literatura.

\section{REFERÊNCIAS}

ABPC. Associação Brasileira de Paralisia Cerebral. o que é paralisia cerebral? Disponível em: $<$ http://paralisiacerebral.org.br/saibamais05.php

>. Acesso em: set. 2015.

ALPINO, A. M. S. Consultoria colaborativa escolar do fisioterapeuta: acessibilidade e participação de alunos com paralisia cerebral. 2008. $190 \mathrm{f}$ Tese (Doutorado em Educação Especial) - UFSCar, São Carlos, SP.

ALVES, A. C. J. A tecnologia assistiva como recurso à inclusão escolar de alunos com paralisia cerebral. 2009. 168 f. Dissertação (Mestrado) - Universidade Federal de São Carlos. São Carlos, SP.

BERSCH, R.; MACHADO, R. Conhecendo o aluno com deficiência física. In: SCHIRMER, Carolina et al. Atendimento educacional especializado: deficiência física. Brasília: MEC/SEESP, 2007.

; SCHIRMER, C. Tecnologia Assistiva no processo educacional. In: BRASIL. Ministério da Educação. Ensaios Pedagógicos: construindo escolas inclusivas. Brasília: MEC/SEESP, 2005.

BODGAN, Robert; BIKLEN, Sari. Investigação qualitativa em educação. Portugal: Porto Editora, 1994.

BRANDÃO, J. S. Bases do tratamento por estimulação precoce da paralisia cerebral ou dismotria cerebral ontogenética. São Paulo: Memnon, 1992.
BRASIL. Comitê de Ajudas Técnicas (CAT). Ata da Reunião VII, de dezembro de 2007 do Comitê de Ajudas Técnicas. Secretaria Especial dos Direitos Humanos da Presidência da República (CORDE/SEDH/PR), 2007.

Constituição da República Federativa do

Brasil. Brasília: Senado Federal, 1988.

Decreto no 3.298, de 20 de dezembro de

1999: regulamenta a Lei no 7.853, de 24 de outubro de 1989, dispõe sobre a Política Nacional para a Integração da Pessoa Portadora de Deficiência, consolida as normas de proteção, e dá outras providências. Disponível em: $<$ https://www.planalto.gov.br/ccivil 03/decreto/ D3298.htm>. Acesso em: ago. 2015.

Decreto 7.611, de 17 de novembro de 2011: dispõe sobre a educação especial, o atendimento educacional especializado e dá outras providências. Disponível em: $<$ https://www.planalto.gov.br/ccivil 03/ ato201 1-2014/2011/decreto/d7611.htm>. Acesso em: 02 mai. 2015.

Política Nacional de Educação Especial na Perspectiva da Educação Inclusiva. Brasília: MEC/SEESP, 2008. Disponível em: $<$ portal.mec.gov.br/arquivos/pdf/politicaeducesp ecial.pdf>. Acesso em: fev. 2015.

GALVÃO FILHO, T. A. Tecnologia assistiva para uma escola inclusiva: apropriação, demanda e perspectivas. 2009. Tese (Doutorado) Universidade Federal da Bahia. Faculdade de Educação, Salvador, BA.

GIL, A. C. Como elaborar projetos de pesquisa. São Paulo: Atlas, 2002.

GOMES, C.; BARBOSA, A. J. G. Inclusão escolar do portador de paralisia cerebral: atitudes de professores do Ensino Fundamental. Revista Brasileira de Educação Especial, Marília, v. 12, n. 1, p. 85-100, jan./abr, 2006.

GUERREIRO, E. M. B. R. Acessibilidade e a educação: um direito constitucional como base para um direito social da pessoa com deficiência. Revista Educação Especial, Santa Maria, v.25, n.43, p.217-232, 2012.

HOHENDORFF, J. V. Como escrever um artigo de revisão de literatura. In: KOLLER, S. H.; COUTO, M. C. P. P; HOHENDORFF, J. V. Manual de produção científica. Porto Alegre: Penso, 2014. p. 39-54.

MANZINI, E. J. Tecnologia assistiva para educação: recursos pedagógicos adaptados. In: BRASIL. Ministério da Educação. Ensaios pedagógicos: construindo escolas inclusivas. Brasília: SEESP/MEC, 2005, p. 82-86. 
; SANTOS, M. C. F. Portal de Ajudas

Técnicas para educação: equipamento e material pedagógico especial para educação, capacitação e recreação da pessoa com deficiência física: recursos pedagógicos adaptados. Brasília: Distrito Federal, MEC/SEESP, 2002.

MATOS, M. A. S. (Org.). Educação especial, políticas públicas e inclusão: desafios da prática e contribuições da pesquisa no NEPPD/FACED/UFAM. Manaus: Vitória, 2012.

MAZOTTA, M. J. S. Educação especial no Brasil: história e políticas públicas. 5. ed. São Paulo: Cortez, 2005.

MOTA, L. S. Centro Educacional para Alunos Especiais à Distância - CEAED. 2007, $149 f$. Dissertação (Mestrado) - Universidade Federal do

Ceará, Fortaleza, CE.

PONSONI, A. Comunicação suplementar e alternativa no discurso narrativo do aluno com paralisia cerebral. 2010 Dissertação (Mestrado) UNESP, Marília, SP.

ROCHA, A. N. D. C.; DELIBERATO, D. Tecnologia assistiva para a criança com paralisia cerebral na escola: identificação das necessidades. Revista Brasileira de Educação Especial, Marília v. 18, n. 1, p. 71-92. Jan/mar., 2012.

SARTORETTO, Mara Lúcia; BERSCH, Rita de Cássia Reckziegel. A educação especial na perspectiva da inclusão escolar: recursos pedagógicos acessíveis e comunicação aumentativa e alternativa. Brasília: Ministério da Educação, Secretaria de Educação Especial, 2010.

SILVA, V. L. Representações sociais e formação de professores: construindo possibilidades para a inclusão escolar de alunos com Paralisia Cerebral. 2008. 121 f. Dissertação (Mestrado em Enfermagem) - Escola de Enfermagem, Universidade Federal de Minas Gerais, Belo Horizonte, MG.

VINENTE, S. O atendimento do escolar com Paralisia Cerebral na rede municipal de ensino em Manaus: a práxis pedagógica no contexto da diversidade. In: MATOS, M. A. S. (Org.). Educação especial, políticas públicas e inclusão: desafios da prática e contribuições da pesquisa no NEPPD/FACED/UFAM. Manaus: Vitória, 2012. p. 185-209.

Recebido para publicação em 14/03/2015

Revisado em 05/10/2015

Aceito em 23/02/2016 